\title{
Meaning in Life
}

An Analytic Study

Thaddeus Metz 


\section{OXFORD}

UNIVERSITY PRESS

Great Clarendon Street, Oxford, Ox2 6DP,

United Kingdom

Oxford University Press is a department of the University of Oxford.

It furthers the University's objective of excellence in research, scholarship, and education by publishing worldwide. Oxford is a registered trade mark of Oxford University Press in the UK and in certain other countries

(C) Thaddeus Metz 2013

The moral rights of the author have been asserted

First Edition published in 2013

Impression: I

All rights reserved. No part of this publication may be reproduced, stored in a retrieval system, or transmitted, in any form or by any means, without the prior permission in writing of Oxford University Press, or as expressly permitted by law, by licence or under terms agreed with the appropriate reprographics rights organization. Enquiries concerning reproduction outside the scope of the above should be sent to the Rights Department, Oxford University Press, at the address above

You must not circulate this work in any other form and you must impose this same condition on any acquirer

Published in the United States of America by Oxford University Press I9 8 Madison Avenue, New York, NY ıoor6, United States of America

British Library Cataloguing in Publication Data

Data available

Library of Congress Control Number: 2013938357

ISBN 978-0-I9-95993I-8

Printed and bound in Great Britain by CPI Group (UK) Ltd, Croydon, CRO 4 YY

Links to third party websites are provided by Oxford in good faith and for information only. Oxford disclaims any responsibility for the materials contained in any third party website referenced in this work. 


\section{1 \\ Introduction}

'You lay a heavy question on me: What is the meaning or purpose of life? It seems to me to be the only question worth asking and one that probably a person ought not spend too much time answering.'

David Small ${ }^{1}$

'The meaning of life, you ask? Being aware of it, I should say.'

Edward Albee ${ }^{2}$

\section{I Finding meaning through the search for it}

I have not taken David Small's counsel not to spend too much time trying to answer the question of what would make a life meaningful. Indeed, after having spent about ten years doing so, I realize that I am sympathetic to the old saying that the meaning of life lies in the search for it, which Edward Albee expresses with grace. Now, no one really buys that, at least as a complete account of meaning in life; I cannot recall a single philosophical work I have read on the topic that even mentions the idea that life's meaning is comprised of the quest for it, let alone takes the idea seriously. However, as I begin to write a book that systematically searches for the most justified answer to the question of what constitutes meaning in life-and as you begin to read it - I want to consider whether there is a kernel of truth to be had here.

I confess that what has largely motivated me to devote a substantial portion of my research time over the past decade to issues of meaningfulness has been an unarticulated sense that doing so would itself be a meaningful enterprise, the sort of thing comparable to, say, rearing children with love or creating a work of art. I have not thought that I have had a moral obligation to write the material that would eventually appear in this book. Nor have I thought that I have been doing something supererogatory, a morally praiseworthy project above and beyond the call of duty. Furthermore, it has not occurred to me that I am becoming a more excellent person, perfecting valuable facets of my human nature, by conducting research into the particular topic

\footnotetext{
I Quote solicited by Moorhead (I988: I79). $\quad 2$ Q Quote solicited by Moorhead (I988: I0).
} 
of life's meaning. In addition, it is doubtful that I am a person who has become all that much happier or better off by virtue of undertaking this research. As most scholars will tell you, it feels great to make an apparent discovery and to receive positive news from publishers, but those feelings are butterflies, beautiful creatures that quickly fly away, abandoning one to the unattractive, heavier feelings of guilt, shame, anxiety, and worry that one is not writing enough, or that one is not writing well enough, or that editors will not accept for publication what one has written well enough, or that people will not read what one has written well enough and published, or that they will read what one has written well enough and published, but not recognize that it is written well enough to critically discuss. That spiral continues for a while.

Instead of being motivated by duty, supererogation, excellence, or happiness, I have been driven to write about what makes a life meaningful because, at some level, I have believed that doing so would itself be meaningful, even if far from the level of the works of Nelson Mandela, Mother Teresa, Albert Einstein, Charles Darwin, Pablo Picasso, Fyodor Dostoyevsky, and the like, in our stereotypical apprehension of them. I am not saying that I thought that conducting research into the meaning of life would be an instrument by which I could eventually obtain meaning from some other, more practical endeavours. The idea has not been, for instance, that my research would eventually lead me to discover with some degree of assurance what constitutes meaning in life, thereby enabling me to close my laptop, get up from my desk and go and make my life meaningful. Although I do believe there are better and worse answers to the question of life's meaning, and I like to think I am often able to distinguish between them with justification, it is not as though I have felt that knowledge of what makes a life meaningful is a necessary tool without which I could not acquire meaning in light of it. Instead, my view has been that finding full-blown knowledge of what makes a life meaningful would be meaningful for its own sake, and, furthermore, that searching for knowledge of meaning would also be meaningful for its own sake, regardless of whether it successfully lands me with knowledge (at least, if I had a reasonable chance of success).

I suspect most readers' orientation to this book is similar. Perhaps some are looking for definite answers, champing at the bit to get to the end of the book, at which point their doubts will have been settled and they will have found a north star by which to guide their travels. I do argue against a wide array of accounts of what makes a life meaningful and proffer my own, which I find most promising. However, the field of systematic enquiry into meaningfulness is too young to expect very firm results at this point in time. It is only in the past three or four decades that a distinct field has arisen with thoughtful and intricate argumentation, and it is rare that more than Io books, chapters, or articles squarely on the meaning of life in English are published in a given year. I conclude that the theory of meaning in life that I favour is the most defensible, given the current state of the academic literature, but I make no stronger claim than that.

Perhaps an offer of the theory of meaning that is most justified relative to the body of English-speaking philosophical writings that exist as of early $20 \mathrm{I} 2$ is enough to 
motivate some who feel lost to read this book. My point is that they, along with what I suspect are most readers, are probably also reading this book out of the hunch that thinking carefully about what makes a life meaningful would itself make their life at least somewhat more meaningful. A philosophical theory of life's meaning should account for that intuition.

In the rest of this chapter, I spell out what I aim to accomplish in this book. I begin by providing some clarity to the nature of the main question I seek to answer (I.2), after which I indicate the methods I use to answer it (I.3). Then, I provide a brief overview of the chapters, which includes a sketch of the answers to the question that I reject and of the answer that I defend (I.4).

\section{I.2 Clarifying the question}

In this section, I bring out what I mean in posing the question of what would make a life meaningful. Some of this is a matter of indicating what the concept of life's meaning inherently includes (or what talk of it essentially connotes), but I do not here aim to provide a thorough, positive analysis of the concept (or definition of terms), something I undertake in Chapter 2. Instead, my focus here is more negative, in the sense of primarily indicating what the concept does not essentially include.

Most people, or at least philosophers, interested in topics readily placed under the rubric of 'the meaning of life' ultimately want to know what, if anything, would confer meaning on their own lives and the lives of those people for whom they care. ${ }^{3}$ Of course, some, perhaps even a substantial minority, might also or instead be interested in considerations of whether the universe has a meaning or of whether the human species does. However, I do not address these 'holist' or 'cosmic' questions in this book. For one, although there is clearly a body of literature addressing these topics, ${ }^{4}$ it is small compared to the number of 'individualist' writings, of which there are well enough to warrant treatment on their own. For another, often asking 'What is the point of it all?' or 'How did we get here?' is a function of a deeper concern to know how, if at all, the existence of individual human beings can be significant.

In any event, in this book I am strictly concerned to address this individualist orientation, so that another title for it could have been Meaning in a Life. When I speak of 'meaningful' and synonyms such as 'significant', 'important', 'matters' and the like, the only bearer that I have in mind is a human person's life. This includes the phrase 'the meaning of life', which several in the literature, unlike me, use to connote ideas about human life as such, not a given human's life. I set aside such holist understandings of the question of life's meaning, so as to make progress on the individualist construal.

I disagree with many theorists of meaning in life who take the 'first-person' perspective, i.e., the question of whether one's own life is meaningful, to be basic in some respect (e.g., Wong 2008). Most of us are concerned about whether, say, the lives of our spouses and children are meaningful, and not merely because the meaning of our own life might depend on the meaningfulness of theirs.

4 Wisdom (I965); Britton (I969); Edwards (I972); Munitz (I986); Cooper (2003: I26-42); Seachris (2009). 
Note that talk of an individual's 'life' being meaningful is vague, and admits of two different understandings, both of which I address. One sense I label 'whole-life', which concerns the respects in which a person's life as an entirety can be meaningful, perhaps from a deathbed perspective, looking back on the story one's life makes up. Contrast this with a 'part-life' sense, where one considers how a segment of a life can be meaningful or not. There are those in the literature who restrict talk of 'meaning' to lives as a whole; they believe that the only bearer of meaning is a person's entire existence as a pattern or narrative, and not any subset of it. That belief could be true, but I submit that, if it were true, it would not be so by definition of phrases such as 'meaning in life'. A time of engaging in prostitution to feed a drug addiction can be characterized without logical contradiction as a 'meaningless period in one's life', as something distinct from a 'meaningless life as a whole'. Or at least that is the way I elect to use the relevant terms. When the distinction is not important to the issue at hand, I gloss it by speaking merely of 'life' being meaningful. At other times, though, particularly when I address whole-lifers who provide substantive arguments for the view that only a complete life is something that can have meaning or not, I make the distinction salient.

Nearly all those writing on meaning in life believe that it comes in degrees, so that, say, some lives as a whole are more meaningful than others (perhaps contra Sartre I946; Britton I969: I89, I92). Note that calling someone's life 'more important' or 'more significant' than another's might be thought to imply some kind of assessment from a moral perspective, but in the present context it does not. One can coherently hold the view that some people's lives are less meaningful, important, etc. than others, or even downright meaningless, and still maintain that people have an equal moral status grounding obligations to help and not to harm. Consider a consequentialist moral theory according to which each individual counts for one in virtue of having a capacity for a meaningful life (cf. Railton I984), or a Kantian perspective that people have a dignity in virtue of their capacity for autonomous choices and meaning is a function of exercising this capacity (Nozick I974: 48-5I). On both views, ethical norms could counsel an agent to help people with comparatively meaningless or unimportant lives, precisely because they are peers with regard to moral standing.

Another element of the question of life's meaning that I take for granted in my enquiry is that meaningfulness, whether of the whole of one's life or a part, is desirable. More strongly, when I speak of 'meaning' and cognate terms, by definition I mean something that is finally, and not merely instrumentally, valuable. Such talk connotes something that is good for its own sake, and not merely as a means to something else distinct from it. There are some in the literature who deem talk of 'meaning' to indicate something that could be evaluatively neutral, a property that, say, an evolutionary biologist would be comfortable invoking. However, I stipulate here that by 'meaning' I am in part essentially conveying something that is worthy for its own sake, something that provides a person with at least some (pro tanto) basic reason to prize it.

Furthermore, I, like most in the field, take specific exemplary instances of great meaning to have been realized by the likes of Mandela, Mother Teresa, Einstein, 
Darwin, Picasso, and Dostoyevsky. I often use the phrase 'the good, the true, and the beautiful' to capture their accomplishments, and the reader should read that figuratively, as a rough way of referring to certain kinds of moral achievement, intellectual reflection, and aesthetic creation. Hence, the reader is cautioned, for instance, not to use a plain sense of 'the good' that would be overly broad for connoting something more than do-gooding, such as pleasure. Insofar as 'the good' least controversially confers meaning on life, it picks out ethical accomplishments such as maintaining integrity in the face of temptation, going beyond the call of duty to help others, helping to pull off a just political revolution, and, at a more everyday level, sustaining friendly and loving relationships. Similarly, the reader should note that 'the true' refers to thinking that need not be literally the truth, and 'the beautiful' picks out artwork that could be original, revealing, and emotionally stirring without necessarily being alluring.

Note that it does not follow from this definition of 'meaningful' that I have analytically ruled out the possibility that Adolf Hitler's life was meaningful. To maintain that talk of 'meaning' essentially connotes something desirable of the sort widely taken to be instantiated by helping others does not logically imply that immoral projects cannot be desirable in the relevant way. For all I have said, Hitler's life conceptually could have been meaningful and even in virtue of having achieved his end of wiping out Europe's Jewish population, a view that some philosophers have found palatable. ${ }^{5}$ To say that Hitler's existence was 'significant', I am contending, would indicate that it was valuable merely in a certain respect, which would leave open the judgements that what he did was seriously immoral and that he had the most reason not to do it.

Just as it is not a logical contradiction to speak of an 'immoral but meaningful life', so it is not to speak of an 'unhappy but meaningful life'. There are many conditions that appear suitably described as 'meaningful misery', with some examples being people who: take care of a sick, elderly parent when doing so would prevent them from pastimes they would find enjoyable; struggle against injustice at the cost of their own peace and harmony; and sacrifice life or limb so that others will survive. If one believes that these lives are not in fact meaningful, that would take argument to show and could not be established merely by definition upon accurately describing them as 'unhappy'.

Similarly, it does not do violence to ordinary linguistic usage, at least among philosophers, to speak of a 'happy but meaningless life', with prominent examples from the literature including: being subject to manipulation and passivity, but feeling cheery because of consumerism and spectacular culture (Marcuse I964; Debord I967); spending life in an experience machine that gives the occupant the vivid impression he is doing sophisticated and interesting things that he is not (Nozick 1974: 42-5); rolling a rock up a hill for eternity and enjoying it because of the way the gods have structured one's brain (Taylor 1987: 679-81); and being taken in by charlatans who make one feel special, say, falsely believing in the fidelity of one's beloved or in the divine status of a charismatic leader (Wolf i997a: 218).

${ }^{5}$ Ellin (I995: 326); Kekes (2000: 30); Belliotti (200I: 7); Frankfurt (2002: 248-9); Wong (2008: I4I). 
So far, I have suggested that talk of 'meaningfulness' (and cognate terms) does not by definition connote anything about rightness or happiness. Conversely, I do not think that 'absurd' is best understood to be a synonym of 'meaningless'. The concept of absurdity, if one is usefully narrow when analysing it, essentially involves the idea of incongruity (Feinberg I980; Martin 2002: 219-24), whereas the concept of meaninglessness does not. For example, Albert Camus (1942) famously maintains that a world without God and a soul fails to fit our expectations for order and justice in the universe, and Thomas Nagel (I97I, I986: 208-32) argues that certain unavoidable standpoints that we take on our lives render them absurd, since they posit contradictory judgement about whether they matter. Even if life were absurd in these ways, it would not follow, by definition, that no individual lives can be meaningful.

Finally, consider the concept of futility (analysed with care by Trisel 2002). Futility is more or less the idea of a repeated failure to obtain one's ends. Given that analysis, a human being's life logically could be meaningless but not futile, for she might have done a good job of realizing ends such as urinating in snow and chewing gum. Conversely, it seems that a life could conceivably be futile but meaningful, for instance, if one believes that meaning in one's life can come from states that one cannot bring about, perhaps being one of God's chosen people.

To sum up, the concept of a meaningful life includes the idea of a human person's existence (and not human life as such) exhibiting a kind of non-instrumental value to some degree, where this value: is exemplified by the good (morality), the true (enquiry), and the beautiful (creativity); is not by definition the same as happiness or rightness; and is logically compatible with absurdity and futility. The related concept, of a meaningless life, indicates the comparative lack of this value in a person's existence, does not necessarily include the presence of futility or absurdity (but might), and is exemplified by a life spent in an experience machine or forever rolling a stone.

This rough account of what I mean when asking what would make a life meaningful is substantially negative in the sense of mainly indicating what the question does not essentially include. As such, it is merely a beginning, with the more positive project of articulating an explicit and comprehensive account of it being undertaken in the following chapter. For now, my goal is merely to put enough flesh onto the skeleton of the question of how (if at all) one's life can be meaningful in order to clarify my project in this book.

\section{I.3 Answering the question}

One could seek to answer the question of what constitutes meaning in life by presenting a list of specific ways to do so. Few in the literature have sought to do that, and even one of those who has admits, 'Lists are boring. They fail to make us stop and think. They fail to illuminate underlying structure' (Schmidtz 200I: I77). The philosophical mind, or at least one major sort of it, seeks more than a list because it seeks order, roughly explanatory unity, amongst diversity. It naturally asks this of a list 
of meaningful conditions: is there something that all the elements on the list have in common? An answer to this question is what I often call a 'theory' or 'principle' of meaning in life. Prominent theories of life's meaning, stated in unrefined ways, include the views that it is constituted by conforming to God's will, putting one's immortal soul into a state of perfection, fulfilling one's strongest desires, or obtaining objective goods in this earthly life. An acceptable theory would be a general principle that entails, and provides a convincing explanation of, the many particular ways in which life can be meaningful.

There might not exist an acceptable theory of life's meaning, in the final analysis, viz., there might be nothing other than a list to be had. However, in order to know that no principle does an acceptable job of accounting for all the elements on the list, one must search for one that does, which is my foremost aim in this book. ${ }^{6}$ And a thorough search by professional philosophers has not been undertaken long at all, having begun in earnest only in the I980s or so.

Finding an acceptable theory would be intellectually satisfying, akin to discovering that the rain, the ocean, and the liquid that runs from the tap and one's eyes are all $\mathrm{H}_{2} \mathrm{O}$. It is a matter of dispute how strongly to take this analogy between scientific claims of identity and value-theoretic claims of it. I favour 'realism' (of the naturalist variety), which is roughly the view that the analogy is strong; there exists a feature in the world to be identified with meaningfulness in the way that $\mathrm{H}_{2} \mathrm{O}$ is identified with water. A bit more carefully, realism is the view that talk about 'life's meaning' refers to a property that obtains independent of our beliefs about it that we can learn about over time largely through probabilistic evidence. Just as we can learn through empirical and fallible methods that the various things we call 'water' are all constituted by the chemical composition $\mathrm{H}_{2} \mathrm{O}$, so, according to realism about value, we can learn in similar ways that the conditions of life we are most firmly inclined to call 'meaningful' are, at bottom, a certain basic composition of being and doing.

I articulate a kind of realist metaphysic later in the book (5.5), ${ }^{7}$ but do not defend it here against the myriad challenges to it; my present aim is to motivate the project of ascertaining what, if anything, all the various meaningful conditions of life have in common, and that would be philosophically important not only if realism were true, but also if it were not. The main competitor to realism is constructivism, roughly the view that a better analogy with a general account of meaning in life would be with the basic rules of grammar. Similar to the way that human beings unconsciously create languages and can find fundamental rules entailing and explaining a wide array of meaningful sentences, we as a society, without much awareness, invent meaningful lives that might well admit of some explanatory unity. This kind of relativism would still make good sense of the theoretical project I undertake in this book, for would it

${ }^{6}$ Some would also suggest, plausibly, that one requires a theory in order to come up with a definite list.

${ }^{7}$ For other applications of realism to issues of meaning in life, see Post (I987: 317-26) and Smith (I997: 2II-2I). 
not be fascinating to discover a general principle that underlies the particular judgements that people in a large and long-standing tradition are inclined to make, upon reflection? If the basic rules governing English would be revealing to apprehend, then so would a fundamental principle capturing judgements of meaning in life of those who have thought most about them, even if they were limited to Western culture. Relativism is consistent with a society's pursuit of deep self-understanding.

I have suggested that the goal of seeking an acceptable theory of meaning in life should appeal to readers with a wide array of metaphysical commitments. In addition, the method I use to achieve this goal should be attractive to those with various epistemological views. In a nutshell, I argue for one theory to the exclusion of others. An argument is a collection of claims in which some claims putatively provide reason to believe another claim, part of which reason is constituted by the fact that the supporting propositions are less controversial than the proposition being supported. A good argument is one in which, for all we can tell, the premises are true, lend evidentiary support to the conclusion, and are weaker than the conclusion.

Often my premises include what I, with the field, call an 'intuition', that is, a judgement of a particular instance of what does or does not confer meaning on life, which judgement is purportedly less controversial than the general principle that is being evaluated in light of it. For instance, it would be a strike against a theory if it entailed that a life of torturing babies for fun would be superlatively meaningful, and it would, in contrast, be a mark in favour of a theory if it could plausibly explain why having composed The Brothers Karamazov conferred meaning on Dostoyevsky's life.

Appealing to such intuitions might suggest a commitment to either foundationalism or coherentism, but in fact it entails neither. I make no suggestion that intuitions are self-justifying, beyond doubt or anything 'foundational'. Conversely, I make no suggestion that intuitions are ultimately justified by virtue of their logical and explanatory fit, or 'reflective equilibrium', with a wide array of other claims. I set aside the debate between foundationalism and coherentism and even their common rival, reliabilism, noting that any plausible philosophical theory of justification or knowledge will entail that argumentation, particularly of the sort that appeals to intuition, is a source of justification. ${ }^{8}$ I rest content by evaluating theories of life's meaning with claims that are plausible, viz., are themselves supported by good arguments, and are initially more compelling than the theories they are invoked to appraise. This method, which prizes logical virtues such as clarity, evidence, principle, counterexample, and inference to the best justification, is the one used as standard by contemporary analytic philosophers, regardless of their epistemological views, such that some would aptly characterize my project as 'analytic existentialism' (Benatar 2004: I-3).

In sum, this book is addressed in the first instance to the professional scholar, and is principally devoted to organizing, clarifying, evaluating, and surpassing the theories

${ }^{8}$ Argumentation of the kind that appeals to intuition is, after all, how epistemologists characteristically aim to justify their favoured theories of justification! 
of life's meaning prominent in the philosophical literature. To obtain focus and to make my task manageable, I focus on English-speaking journals and books written by academic philosophers. I do discuss works originally written in, say, French and German, but they are mostly classic sources. To the best of my knowledge, the most systematic attempt to develop an acceptable theory of meaning in life has been undertaken by contemporary Anglo-American analytic philosophers. ${ }^{9}$ Furthermore, the amount of literature they have produced on the topic is large enough to work through and evaluate on its own. There is, of course, also literature on meaning in life in non-philosophical fields such as psychology and religion, which I draw upon here and there, but not in any thorough way. Although I have worked to make this book accessible to a wide audience, by defining my terms and minimizing the use of jargon, it is by a philosopher about philosophy for philosophers.

\section{I.4 Overview of the answer}

The book proceeds developmentally, with later chapters assuming and building on claims established in earlier ones; that is, I have sought to provide more than a mere patchwork of essays. It would, nonetheless, be feasible for the reader already well acquainted with contemporary normative philosophy to jump around as befits her interests, for I routinely indicate the numbered sections where certain claims are more fully articulated and defended.

The book consists of three major parts, with the first part fleshing out meaningfulness as an evaluative category distinct from others, discussing features of it that are compatible with the overwhelming majority of competing theories of what constitutes it. In the second chapter, I continue the project begun here of indicating what talk of 'life's meaning' connotes. I first critically examine the major definitions in the literature, which attempt to provide a single necessary and sufficient condition for a theory to be about meaning as opposed to some other value, and I argue that they are all vulnerable to counterexamples. I then present my own, complex analysis that is a 'family resemblance' view, holding roughly that theories of meaning in life are united by virtue of being answers to a variety of related and substantially overlapping questions that cannot be reduced to anything simpler. Such questions include: 'Which ends intrinsically merit striving for, beyond one's own pleasure? How should a human person transcend her animal nature? What are the features of a life that warrant great esteem or admiration?'

In the third chapter, I take up the issue of which facets of a life are capable of exhibiting meaning or the lack of it: only its parts, only the life as a whole, or both? I defend the latter, mixed answer, providing reason to reject both a pure whole-life

9 Philosophers in, say, the French, sub-Saharan, and Chinese traditions have tended to address the topic of life's meaning using more particularist, phenomenological, or hermeneutic approaches. 
view, according to which only the narrative relationships among the parts of a life are what can be meaningful (or meaningless), as well as a pure part-life view, according to which only segments of a life in themselves are what can be meaningful. I maintain that both a slice of one's life, as well as a life's overall pattern, can exhibit meaningfulness or meaninglessness. I develop a model to capture the whole-life dimensions of meaning, laying out, in a way that exhibits a progressive logic, several distinct respects in which the pattern of a life can plausibly affect its meaning.

I will have argued in the second chapter that a large part of what we mean by 'meaning in life' is a kind of final good distinct from pleasure as such. In the fourth chapter, the last of part one, I highlight some of the substantive value-theoretic implications of the contrast. After first arguing that there is a largely unrecognized disvaluable dimension of meaning, parallel to the way that pain is the opposite of pleasure, I focus on the respects in which meaningfulness and pleasure differ with regard to issues such as: which attitudes it is appropriate to have toward them; how much luck can influence them; and when we should prefer them in a life. Regarding the last issue, I demonstrate that the category of meaning in life ultimately explains much of the literature addressing Derek Parfit's fascinating discussion of 'bias toward the future', providing unity to sundry intuitions about when pleasure, relationships, creativity, and other goods, as well as bads, are preferable in a life.

The second and third parts of the book critically discuss theories of life's meaning, which, at the broadest level, I differentiate metaphysically, by the kind of property taken to constitute it. The second part, comprising Chapters 5 through 8 , addresses supernaturalist theories according to which meaning in life consists of engagement with a spiritual realm. Such a general view implies that if neither God nor a soul nor any other spiritual being or force existed, then all our lives would be meaningless. My aims in this part include specifying the most defensible versions of supernaturalism, bringing out what fundamentally motivates them, and ultimately concluding that life can be meaningful in the absence of anything supernatural.

I begin by addressing the most influential form of supernaturalism, the God-centred theory that meaning in life is constituted by fulfilling His purpose (or carrying out His commands). In Chapter 5, I spell out this 'purpose theory' in detail and critically discuss the major rationales for it from the literature. I use the most space to address the most powerful and interesting argument for purpose theory, namely, that God's will alone could ground an objective or universal morality that is necessary for life to make any sense. I grant that-contra standard 'Euthyphro' objections in the literaturefacts about God probably could entail an ethic that applies to all human persons, but I argue that they would not best explain it, and hence that a divine command morality is unlikely to justify purpose theory.

In Chapter 6, I consider arguments against purpose theory, first rebutting some influential objections to it in the literature, many of which include the claim that it would be disrespectful and hence immoral for God to give us a purpose. I then present a new, and what I take to be more powerful, objection to the idea that God's purpose 
grounds meaning. In a nutshell, I argue that the best explanation of why God alone might constitute meaning in life is that God has perfections that we cannot conceivably exhibit, features such as simplicity and infinity, which are widely taken to be incompatible with purposiveness. With this argument, I maintain that the reason to believe God-centred theory in general undercuts the particular, purposive version of it that has dominated the field.

In the seventh chapter, I articulate the conceptions of meaning in life that a God-centred theorist ought to find attractive, supposing that my argument against purpose theory is sound. I also aim in this chapter to specify the most defensible versions of soul-centred theory, views that do not take God, but rather an immortal, non-physical substance constitutive of one's identity, to be the key to meaning in life. I address major rationales in the literature for thinking that having a soul is necessary for meaning in life, pointing out that they are all deductively invalid and inductively weak, reconstructing them, and then showing this: any promising argument for a soul-centred theory is equally an argument for a God-centred theory, because all such arguments ultimately rely on the perfection thesis', the claim that meaning in life is possible only if one engages with some maximally conceivable value.

Before questioning the perfection thesis that underlies supernaturalism in Chapter 8, I conclude Chapter 7 by arguing that extant objections to soul-centred theory are weak. In particular, I take up some influential arguments for thinking that immortality would be sufficient for meaninglessness, providing new reasons to reject them. For example, against the claim that immortality would get boring, I do not argue, as most do, that it need not, but rather that, even if it did, it could still be meaningful. And against those who argue that immortality would make us unappreciative and unmotivated, I point out that it is belief in immortality, not immortality itself, that would be the culprit.

Chapters 5 through 7 will have demonstrated that the most promising motivation for holding a God-centred or soul-centred theory of meaning in life is the 'perfection thesis', the idea that meaning requires engagement with some kind of maximally conceivable or ideal value. In Chapter 8 , I provide reasons to favour some version of the 'imperfection thesis' over the perfection thesis, defending the idea that there can be meaning in life in the absence of relating to anything perfect or spiritual. After rejecting the adequacy of extant arguments against the perfection thesis and supernaturalism, I present a new one, to the effect that most readers cannot coherently hold these views, given plausible beliefs to which they are already committed. Basically, if we had conclusive evidence for supernaturalism and its perfection thesis, then we would know that both perfection and meaningfulness exist, but while we do know that the latter exists, we do not know that the former does. My overall conclusion is that while neither God nor a soul is necessary for meaning in life, they would probably enhance it, something those who reject supernaturalism have tended not to explain, or even to acknowledge. 
At the end of Chapter 8, I also begin to develop the imperfection thesis in detail, with particular focus on how much less than perfect value one must engage with in order for one's life to count as meaningful on balance, as opposed to meaningful merely to some extent. I construct a new account according to which a life is meaningful all things considered if it is not far from the maximum goodness constitutive of meaning available to humanity in the physical universe, given the laws of nature. I argue that this principle avoids counterexamples to several existing rivals, such as the views that a life is on balance meaningful if it realizes a certain percentage of meaning available to the individual, or if it has (much) more than the average amount of meaning for members of the species.

Part three, composed of Chapters 9 through I3, addresses the other major perspective on meaning in life, naturalism, the view that certain, imperfect ways of living in a purely physical world would be sufficient to make life meaningful. Overall, I argue against the most plausible extant versions of naturalism, and then develop a new naturalist theory that both avoids and explains the problems facing others and that is, I contend, the most justified theory of meaning in life at present.

The ninth chapter takes up subjective naturalism, the theory that a person's life is more meaningful, the more it obtains the objects of propositional attitudes such as desires or goals. I first reject arguments for subjectivism, after which I reject subjectivism itself for the usual reason, that it has counterintuitive implications regarding which lives are meaningful. I address underexplored versions of subjectivism that are more likely to avoid this objection, e.g., intersubjectivism, but ultimately argue that they fail to do so.

The tenth chapter begins my attempt to develop the best version of the broad objective naturalist view that one's existence is significant insofar as one lives in a physical world in ways that are valuable not merely because they are the object of anyone's propositional attitudes. Here, I critically examine two of the three major forms of objectivism that are in the literature. I start by refuting the view of life's meaning that currently dominates the field, the theory that the combination of subjective attraction to objective attractiveness is necessary and sufficient for meaning. I argue that however 'subjective attractiveness' is construed, it is not necessary for meaning, and then point out that everyone's talk of 'objective attractiveness' is much too vague, requiring another theory altogether to fill it out.

The second major form of objectivism that I address is consequentialism, the main version of which is the utilitarian view that meaning comes from making those in the world better off. I reject this theory not only on the ground that there are other plausible ways to obtain meaning besides promoting well-being, but also because of its consequentialist structure. Regarding the latter, I argue that there are three major respects in which promoting well-being (or some other final good such as virtue) insufficiently captures meaning in life, and that certain 'agent-relative' ways of responding to final goodness are essential for an adequate theory. I do acknowledge, though, that under some circumstances the long-term consequences can confer meaning on life, and that a satisfactory theory must account for this judgement. 
In Chapter II, I turn to the third major variant of objectivism, according to which meaning in life is constituted primarily by some kind of non-consequentialist relationship to certain values. According to this broad perspective, meaning comes from positive engagement with mind-independent goods in the physical world, where this is not merely a matter of seeking to promote them however one can, wherever one can and as much as one can. I argue that all the major extant non-consequentialist theories are counterintuitive, unable adequately to capture the exemplars of meaning, viz., the true, the good, and the beautiful.

Next, in Chapter I2, I develop a novel, non-consequentialist theory which, I argue, avoids all the problems facing its rivals. According to my favoured principle, one's life is more meaningful, the more one contours one's rational self (in a way that does not violate certain moral constraints) toward fundamental objects, i.e., conditions of human life that are largely responsible for many of its other conditions. I demonstrate how this 'fundamentality theory' plausibly accounts for the meaningfulness of the good, the true, and beautiful, and avoids the objections to other theories while incorporating their kernels of truth. For examples of the latter, I explain how the fundamentality theory accommodates the ideas that meaning in life could be enhanced by, but does not require: relating to God, exhibiting subjective attraction to what one is doing, and improving others' lives.

Parts two and three will have discussed the theoretical conditions that could make life meaningful, and in them I will have provisionally accepted the claim that some lives have meaning in them. Confirming that some people's lives are in fact meaningful is my aim in the concluding chapter of the book. Nihilists or pessimists are those who contend that our lives are all utterly meaningless, i.e., that some necessary conditions for a meaningful life fail to obtain for any human beings. In Chapter I3 I critically discuss two influential arguments for nihilism, aiming to provide reason to doubt them. In both cases, I show that nihilists implicitly appeal to claims that are in tension with each other, so that nihilist arguments fail to give one sufficient reason to reject the pre-theoretic judgement, shared by most readers, that some lives are indeed meaningful.

I close the book with an epilogue that returns to the issue that opened the present, introductory chapter. It addresses the respect in which the fundamentality theory of what constitutes meaning in life that I articulate and defend explains the intuition that the search for meaning is itself a source of meaning. I conclude that the book's central thesis justifies its own composition. 